Article

\title{
Amelioration of Ethanol-Induced Gastric Ulcers in Rats Pretreated with Phycobiliproteins of Arthrospira (Spirulina) Maxima
}

\author{
Oscar Guzmán-Gómez ${ }^{1}$, Rosa Virginia García-Rodríguez ${ }^{2}$, Lucía Quevedo-Corona ${ }^{3}$ (i), \\ Ricardo Pérez-Pastén-Borja ${ }^{1}{ }^{(1)}$, Nora Lilia Rivero-Ramírez ${ }^{4}$, Emmanuel Ríos-Castro ${ }^{5}$ (D), \\ Salud Pérez-Gutiérrez ${ }^{6}$, Julia Pérez-Ramos ${ }^{6}$ and Germán Alberto Chamorro-Cevallos ${ }^{1, * \text { (D) }}$ \\ 1 Departamento de Farmacia, Escuela Nacional de Ciencias Biológicas, Instituto Politécnico Nacional, \\ 07738 Ciudad de México, Mexico; oguz1985@live.com.mx (O.G.-G.); pastenrich@yahoo.com.mx (R.P.-P.-B.) \\ 2 Unidad de Servicios de Apoyo en Resolución Analítica, Universidad Veracruzana, Xalapa, \\ 91190 Veracruz, Mexico; rosga74@hotmail.com \\ 3 Departamento de Fisiología, Escuela Nacional de Ciencias Biológicas, Instituto Politécnico Nacional, \\ 07738 Ciudad de México, Mexico; quevedocorona@hotmail.com \\ 4 Departamento de Morfología, Escuela Nacional de Ciencias Biológicas, Instituto Politécnico Nacional, \\ 11350 Ciudad de México, Mexico; jazzband19@hotmail.com \\ 5 Unidad de Genómica, Proteómica y Metabolómica, LaNSE, Cinvestav-IPN, \\ 07360 Ciudad de México, Mexico; eriosc@cinvestav.mx \\ 6 Departamento de Sistemas Biológicos, Universidad Autónoma Metropolitana-Xochimilco, \\ Calzada del Hueso 1100, Col. Villa Quietud, Coyoacán, Ciudad de México 04960, Mexico; \\ msperez@correo.xoc.uam.mx (S.P.-G.); jperez@correo.xoc.uam.mx (J.P.-R.) \\ * Correspondence: gchamcev@yahoo.com.mx; Tel.: + 52-57296300 (ext. 52398)
}

Received: 19 April 2018; Accepted: 8 June 2018; Published: 13 June 2018

\begin{abstract}
Phycobiliproteins of Arthrospira (Spirulina) maxima have attracted attention because of their potential therapeutic antioxidant properties. The aim of this study was to assess the possible antiulcerogenic activity of these phycobiliproteins (ExPhy) against ethanol-induced gastric ulcers in rats. To explore the possible mechanisms of action, we examined antioxidant defense enzymes (e.g., catalase, superoxide dismutase, and glutathione peroxidase), as well as the level of lipid peroxidation (MDA) and the histopathological changes in the gastric mucosa. Intragastric administration of ExPhy $(100,200$, and $400 \mathrm{mg} / \mathrm{kg}$ body weight) significantly lowered the ulcer index value compared to the ulcer control group $(p<0.05)$. The greatest protection was provided by the concentration of $400 \mathrm{mg} / \mathrm{kg}$. The histological study supported the observed gastroprotective activity of ExPhy, showing a reduced inflammatory response. Moreover, the alcohol-induced decrease in stomach antioxidant enzyme activity found in the ulcer control group was prevented by ExPhy pretreatment. Furthermore, ExPhy reversed the ethanol-induced increase in lipid peroxidation. In summary, the antiulcerogenic potential of ExPhy may be due, at least in part, to its anti-oxidant and anti-inflammatory effects.
\end{abstract}

Keywords: antiulcerogenic; Arthrospira (Spirulina) maxima; phycobiliproteins; ethanol

\section{Introduction}

Stomach ulcers, one of the most common gastrointestinal disorders, affect people of all ages around the world [1]. Under normal conditions, the integrity of the stomach mucosal barrier is maintained by an equilibrium between irritation and defensive factors [2]. When the gastric mucosa is continuously exposed to extremely aggressive agents, such as non-steroid anti-inflammatory drugs 
(NSAIDs), nutritional deficiencies, smoking, stress, and excessive ingestion of ethanol, this equilibrium can be jeopardized and the risk of developing a gastric ulcer increases [3-6].

In the gastrointestinal tract, exposure to alcohol can damage the motility of the esophagus, stomach, and gut as well as the capacity of gut absorption. It can generate mucosal damage and even carcinogenesis $[7,8]$. Ethanol is a harmful agent associated with multiple pathologies and is applied orally in experimental animals to cause acute gastric lesions and ulcers $[9,10]$. The mechanism of ethanol-induced damage is complex and not fully understood. Ethanol produces a disruption in the integrity of the gastric mucosal barrier through exfoliation of cells, thus increasing mucosal permeability and in some cases provoking bleeding $[3,11]$. The extravasation of neutrophils to the site of injury triggers elevated concentrations of reactive oxygen species (ROS) and other mediators of inflammation, causing oxidative damage with deleterious effects on cells. Oxidative stress has been shown to play a role in alcohol-induced gastric mucosal damage [12,13].

Spirulina maxima is a blue-green alga, now given the name Arthrospira maxima (Am). This cyanobacterium has been used as food since antiquity, with some of the first historical records coming from the Aztec civilization and the early inhabitants of Central Africa [14,15]. Due to its high content of proteins (mainly phycocyanin and allophycocyanin), vitamins, amino acids, minerals, and essential fatty acids, it has been the object of several pharmacological studies [16]. Am has been reported as having anti-inflammatory, immunostimulatory, antiviral, and antioxidant activity [17-20], as well as producing anti-hepatotoxic and anti-nephrotoxic effects and improving vascular reactivity [21-23]. These effects have been related to the antioxidant activity of Am, while others are attributed to some of its active ingredients, such as phycobiliproteins, which decrease oxidative stress $[19,24]$. Various studies have shown that extracts of Am rich in phycobiliproteins exhibit relevant pharmacological properties, including anti-teratogenic and neuroprotective effects, antigenotoxic properties, anti-inflammatory, and antioxidant activities, and protection against colitis [19,25-28]. However, to our knowledge, there are no reports on the anti-ulcerative activities of phycobiliproteins from Am.

Hence, the aim of the present study was to assess the gastroprotective effects of an extract of Am rich in phycobiliproteins (ExPhy) on ethanol-induced gastric ulcers in rats. Accordingly, evaluation was made of some antioxidant and oxidative markers as well as histopathological damage.

\section{Materials and Methods}

\subsection{Preparation of the Phycobiliprotein Extract (ExPhy)}

ExPhy was prepared as described by Cruz de Jesús et al. [29], with some modifications. Three grams of Am powder (AEH Spiral Spring, Mexico City) were suspended in $12 \mathrm{~g}$ of phosphate buffer $(20 \mathrm{mM}, \mathrm{pH} 7)$ and stirred at room temperature (r.t.) for $5 \mathrm{~min}$. The solution was then subjected to three cycles of freezing and thawing, being frozen at $-70^{\circ} \mathrm{C}$ and thawed at r.t. Subsequently, the mixture was shaken for $1 \mathrm{~h}$ at r.t., followed by centrifuging the crude extract of phycobiliproteins at 18,000 rpm for $30 \mathrm{~min}$ at $4{ }^{\circ} \mathrm{C}$ in a Beckman Coulter Avanti j-30I centrifugue (Beckman Coulter, Brea, CA, USA). The blue supernatant obtained was separated and again centrifuged at 22,000 rpm, discarding the green precipitate after each centrifugation step. Finally, the supernatant was lyophilized and stored (protected from light) at $-20^{\circ} \mathrm{C}$.

The phycobiliprotein concentration in the supernatant was calculated from absorption measurements at 562, 620, and $652 \mathrm{~nm}$. Equation (1) was used for estimating C-phycocyanin (C-PC) and Equation (2) for allophycocyanin (APC) [30]:

$$
\begin{aligned}
& \text { C-PC }(\mathrm{mg} / \mathrm{mL})=[\mathrm{A} 620-0.474(\mathrm{~A} 652)] / 5.34 \\
& \text { APC }(\mathrm{mg} / \mathrm{mL})=[\mathrm{A} 652-0.208(\mathrm{~A} 620)] / 5.09
\end{aligned}
$$

The purity of C-PC and APC extracts was also evaluated, finding C-PC with an A620/A280 absorbance ratio and APC with an A652/ A280 ratio [31]. 


\subsection{LC-MALDI-MS/MS and Data Analysis}

Sodium dodecyl sulfate-polyacrylamide gel electrophoresis (SDS-PAGE) was performed according to the Gallagher method [32], with a separating gel of $12 \%$ and a stacking gel of $5 \%$ acrylamide. An electrophoresis was run with $50 \mu \mathrm{g} / \mathrm{mL}$ ExPhy at $120 \mathrm{~V}$ for $90 \mathrm{~min}$. Resolved proteins were visualized with Coomassie Brilliant Blue (G250) staining. Four fragments from SDS-PAGE were enzymatically digested according to the modified protocol of Shevchenko et al. [33]. The resulting tryptic peptides were concentrated at an approximate volume of $10 \mu \mathrm{L}$. Then, $9 \mu \mathrm{L}$ were loaded into a ChromXP Trap Column C18-CL precolumn (Eksigent, Redwood City, CA, USA), with $350 \mu \mathrm{m} \times 0.5 \mathrm{~mm}$, a $120 \mathrm{~A}^{\circ}$ pore size and a $3 \mu \mathrm{m}$ particle size, desalted with $0.1 \%$ TFA in $\mathrm{H}_{2} \mathrm{O}$ at a flow rate of $5 \mu \mathrm{L} / \mathrm{min}$ for $10 \mathrm{~min}$. Then, peptides were loaded and separated on a Waters BEH130 C18 column (Waters, Milford, MA, USA), with $75 \mu \mathrm{m} \times 150 \mathrm{~mm}$, a $130 \mathrm{~A}^{\circ}$ pore size and a $1.7 \mu \mathrm{m}$ particle size, using an HPLC Ekspert nanoLC 425 (Eksigent, Redwood City, CA, USA). Mobile phase A was $0.1 \%$ trifluoroacetic acid (TFA) in $\mathrm{H}_{2} \mathrm{O}$ and mobile phase $\mathrm{B} 0.1 \%$ TFA in acetonitrile (ACN) at a flow rate of $300 \mathrm{~nL} / \mathrm{min}$, with the following gradient: $0-3 \mathrm{~min}, 10 \% \mathrm{~B}(90 \% \mathrm{~A}) ; 35 \mathrm{~min}, 60 \% \mathrm{~B}(40 \% \mathrm{~A})$; 36-45 min, 90\% B (10\% A); 46-120 min, 10\% B (90\% A). Eluted fractions were automatically mixed with a solution of $2 \mathrm{mg} / \mathrm{mL}$ of $\alpha$-Cyano-4-hydroxycinnamic acid (CHCA) in $0.1 \%$ TFA and $50 \%$ ACN as a matrix, spotted in a stainless-steel plate of 384 spots with a MALDI Ekspot (Eksigent, Redwood City, CA, USA), with a spotting velocity of $30 \mathrm{~s}$ per spot at a matrix flow of $1.6 \mu \mathrm{L} / \mathrm{min}$. The spots generated were analyzed by a MALDI-TOF/TOF 4800 Plus mass spectrometer (ABSciex, Framingham, MA, USA). Each MS spectrum was acquired by accumulating 1000 shots in a range of $\mathrm{m} / \mathrm{z} 850-4000$ with a laser intensity of 3100 . The 100 most intense ions with a minimum signal-noise $(\mathrm{S} / \mathrm{N})$ of 20 were programmed to fragment. The MS/MS spectra were obtained after fragmentation of selected precursor ions by using collision-induced dissociation (CID), acquired by 3000 shots with a laser intensity of 3800. The MS/MS spectra were compared to the Am CS-328 database (downloaded from Uniprot, 5505 protein sequences) with Protein Pilot software v. 2.0.1 (ABSciex, Framingham, MA, USA) and Paragon algorithm [34]. Search parameters were: carbamidomethylated cysteine, trypsin as a cut enzyme, all biological modifications and amino acid substitutions set by the algorithm, and phosphorylation emphasis and gel-based ID as special factors. The detection threshold was considered at 1.3 to acquire $95 \%$ confidence, and the identified proteins observed a local FDR of $5 \%$ or less. These proteins were grouped by the ProGroup algorithm in the software to minimize redundancy.

\subsection{Animals}

Male Wistar rats (170-250 g) were supplied from the breeding colony of the Autonomous University of Hidalgo State (UAEH). The animals were maintained in cages with raised floors and wide mesh (to prevent coprophagy), in a separate animal room under standard conditions of temperature $\left(22 \pm 1^{\circ} \mathrm{C}\right)$ and a $12 \mathrm{~h} \mathrm{light/dark}$ cycle. They were fed a standard diet, with water provided ad libitum throughout the experiment. Prior to inducing ulcers, the rats were fasted for $22 \mathrm{~h}$. After each experiment, the animals were euthanized in a carbon dioxide euthanasia chamber. The current protocol was accepted by the Ethics Committee of the National School of Biological Sciences (CEI-ENCB-08-2016). All procedures and handling of the animals were in accordance with the Mexican Official Regulation (NOM ZOO-062-200-1999) entitled “Technical Specifications for Production, Care, and Use of Laboratory Animals".

\subsection{Drugs and Chemicals}

Omeprazole was acquired from Sigma-Aldrich (St. Louis, MO, USA). Thiobarbituric acid (TBA) and trichloro acetic acid (TCA) were purchased from Merck (Darmstadt, Germany). SOD and GPx were obtained from Randox, Mexico city. Other reagents and solvents, procured from local sources, were of analytical grade. 


\subsection{Antiulcer Activity and Experimental Design}

The assay was carried out with the methodology described by Almasaudi et al. [35], with some modifications. The animals were randomly divided into six groups $(n=6)$. All treatments were administrated by intragastric gavage for eight consecutive days, with the gastric ulcer induced on the last day with $80 \%$ ethanol solution $(1 \mathrm{~mL} /$ animal). Group I (vehicle control) received the vehicle only ( $10 \mathrm{~mL} / \mathrm{kg}$ body weight (bw) of $1 \%$ Tween- 80 aqueous solution). For all other groups, an ulcer was induced on the last day of treatment, one hour after administering the corresponding compound. Group II (ulcer control) was given the vehicle, group III $40 \mathrm{mg} / \mathrm{kg}$ bw omeprazole, group IV, V and VI the different concentrations of ExPhy (100, 200 and $400 \mathrm{mg} / \mathrm{kg}$ bw, respectively).

One hour after inducing an ulcer, animals were sacrificed. The stomachs were excised, filled by injecting $2.5 \mathrm{~mL}$ of a $4 \%$ formaldehyde solution, and put in a beaker with formaldehyde. After $10 \mathrm{~min}$, the stomachs were opened over the greater curvature and rinsed with saline solution $(0.9 \%)$ to remove the blood clots. Thereafter, each gastric sample was placed on a slide. The gastric damage area $\left(\mathrm{mm}^{2}\right)$ was determined with "Image J" image processing software. The Ulcer Index (UI) for each rat was calculated with the following formula:

$$
\mathrm{UI}=\left(\mathrm{TAML}\left(\mathrm{mm}^{2}\right) \times 100\right) /\left(\mathrm{TMA}\left(\mathrm{mm}^{2}\right)\right)
$$

where TMA is the total mucosal area and TAML the total area of mucosal lesion of each rat [36]. The protection percentage (PP) was calculated using the following formula:

$$
\begin{gathered}
\mathrm{UI}=\left(\mathrm{TAML}\left(\mathrm{mm}^{2}\right) \times 100\right) /\left(\mathrm{TMA}\left(\mathrm{mm}^{2}\right)\right) \\
\mathrm{PP}=(\mathrm{UI} \text { control }- \text { UI treated }) /(\mathrm{UI} \text { control }) \times 100
\end{gathered}
$$

where UI control is the ulcer index of the ulcer control (group II) and UI treated is the ulcer index of the treated group (groups III-VI) [37]. From the three concentrations tested for ExPhy, the one with the least UI was adopted for all other tests.

\subsection{Stomach Tissue Preparation}

In a second experiment, another series of four groups of rats were formed. After the eight days of the corresponding treatments, the ulcer was induced and the rats were sacrificed (see previous section). The stomachs were extracted, cut along the greater curvature, and gently rinsed with cold phosphate buffer (PBS) (pH 7.4). A portion of each stomach tissue (0.5 g) was cut into small pieces and $4.5 \mathrm{~mL}$ of cold PBS were added. The mixture was homogenized on ice with an Ultra-turrax homogenizer (T18, IKA, Staufen im Breisgau, Germany) and a Polytron (Newtown, CT, USA) handheld homogenizer, and then tissue homogenates were centrifuged for $12 \mathrm{~min}$ at $12,000 \mathrm{rpm}\left(4^{\circ} \mathrm{C}\right)$. The supernatants were divided into aliquots and conserved at $-20^{\circ} \mathrm{C}$ until the biochemical analysis.

\subsection{Biochemical Analysis}

Gastric activity of glutathione peroxidase (GPx) was determined with a commercial kit Ransel RS504 (Crumlim, Country Antrim, UK), based on the method developed by Plagia and Valentine [38]. GPx catalyzes the oxidation of glutathione by cumene hydroperoxide. In the presence of glutathione reductase (GR) and NADPH, the oxidized glutathione is immediately converted to the reduced form with concomitant oxidation of NADPH to NADP+. The decrease in absorbance was measured after 1 and $2 \mathrm{~min}$ at $340 \mathrm{~nm}$, with enzyme activity being directly proportional to the rate of change.

Superoxide dismutase activity (SOD) was assessed according to the method of McCord and Fridovich [39] with a Ransod SD125 Kit (Crumlim, Country Antrim, UK). The method employs xanthine and xanthine oxidase to generate superoxide radicals, which react with 2-(4-iodophenyl)-3(4-nitrophenol)-5-phenyltetrazolium chloride (INT) to form a red formazan dye. SOD inhibits the 
reaction by converting the superoxide radical to oxygen. The SOD activity was determined as the degree of inhibition of this reaction, measured by absorbance at $505 \mathrm{~nm}$.

Catalase activity (CAT) in gastric tissue was evaluated by tracking the rate of decomposition of $\mathrm{H}_{2} \mathrm{O}_{2}$ in the presence of CAT at $240 \mathrm{~nm}$ [40].

The protein concentration in supernatants was established by the Bradford method [41], using bovine serum albumin as a standard. This assay involves the binding of Coomassie Brilliant Blue G-250 dye to proteins at r.t. When the dye binds to the protein, it is converted from an unstable form (red in color) to a stable unprotonated form (turning blue). The blue protein dye is detected at $595 \mathrm{~nm}$.

\section{Lipoperoxidation Assessment}

The content of malondialdehyde (MDA) was determined in each of the supernatants by the thiobarbituric acid reactive substances (TBARS) assay, as described by Esterbauer and Cheeseman [42]. To $0.5 \mathrm{~mL}$ of gastric mucosal homogenates were added $1.0 \mathrm{~mL}$ of reactive mixture containing $0.375 \%$ of TBA and $15 \%$ of trichloroacetic acid (TCA) in $0.20 \mathrm{~N} \mathrm{HCl}$. After incubation for $15 \mathrm{~min}$ in boiling water, the samples were cooled and centrifuged at $1000 \mathrm{rpm}$ for $10 \mathrm{~min}$ at $4{ }^{\circ} \mathrm{C}$. The absorbance of the supernatant was measured at $532 \mathrm{~nm}$ and the concentration of MDA was calculated with an extinction coefficient of $156,000 \mathrm{M}^{-1} \mathrm{~cm}^{-1}$.

\subsection{Histopathological Examination}

After determination of the UI, the stomachs of each group were fixed in $10 \%$ formalin solution for $24 \mathrm{~h}$. Subsequently, they were dehydrated by immersing them in ascending concentrations of alcohol solutions (70-100\%) and in paraffin. Slides of stomach slices of $4-5 \mu \mathrm{m}$ thickness were prepared and stained with hematoxylin and eosin (H\&E) and then analyzed under light microscope at $20 \times$ and $40 \times$ for pathological changes, including necrosis, edema, vasocongestion, eosinophilic infiltration, and glandular damage. All slides were photographed with Zeiss Axiophot microscopy (Thornwood, NY, USA).

\subsection{Statistical Analysis}

Statistical analysis was carried out with SigmaPlot version 12.0 (Systat Software, San Jose, CA, USA). All data are expressed as the mean \pm standard error of the mean (SEM). One-way analysis of variance (ANOVA) and Dunnett's post hoc test were applied, comparing the treated groups with the ulcer control group; statistical significance was attributed at $p<0.05$.

\section{Results}

\subsection{Evaluation of Phycobiliprotein Content and Purity of ExPhy}

The phycobiliprotein (C-PC and APC) content and purity of ExPhy were evaluated (Table 1). C-PC purity was found to be 0.86 and APC purity 0.81 . The content of C-PC was $0.40 \mathrm{mg} / \mathrm{mL}$ and of APC $0.56 \mathrm{mg} / \mathrm{mL}$.

\subsection{LC-MALDI-MS/MS Analysis}

Liquid chromatography (HPLC) along with mass analysis by MALDI-MS/MS was carried out to identify and characterize the protein components of ExPhy, isolated from Arthrospira maxima. Nine different proteins were identified that belong to phycobilisomes, which is a light-harvesting macromolecular complex (Table 2). The spot number (band of gel), accession number, protein name, unused, \% coverture (\% Cov), and molecular weight are reported. Other proteins were also detected (their specific data are summarized in Table S1). 
Table 1. Concentration and purity ratio of ExPhy.

\begin{tabular}{ccc}
\hline Phycobiliprotein & Concentration $(\mathbf{m g} / \mathbf{m L})$ & Purity Ratio A620/A280 (C-PC) A652/A280 (APC) \\
\hline C-PC & 0.40 & 0.86 \\
APC & 0.56 & 0.81 \\
\hline
\end{tabular}

C-PC, Phycocyanin C; APC, Allophycocyanin; ExPhy, extract rich in phycobiliproteins.

Table 2. Results of different protein spots identified by MALDI-MS/MS.

\begin{tabular}{|c|c|c|c|c|c|c|}
\hline No. & Spot No. & Accession & Protein & Unused & $\% \operatorname{Cov}$ & MW (Da) \\
\hline 1 & $1,2,3,4$ & $\operatorname{tr}$ IQ8VRJ2 & Phycocyanin alpha chain & 16 & 69.75309 & 17,600 \\
\hline 2 & $1,2,3,4$ & tr | Q7BA94 & Phycocyanin beta chain & 10.44 & 78.48837 & 18,094 \\
\hline 3 & $1,2,3,4$ & $\operatorname{tr} \mid \mathrm{B} 5 \mathrm{VUA} 2$ & Allophycocyanin, beta subunit & 8 & 82.60869 & 17,330 \\
\hline 4 & $1,3,4$ & $\operatorname{tr} \mid \mathrm{B} 5 \mathrm{~W} 3 \mathrm{~K} 3$ & Allophycocyanin, beta subunit & 4.85 & 56.80473 & 18,442 \\
\hline 5 & $1,2,3,4$ & $\operatorname{tr} \mid \mathrm{B} 5 \mathrm{~W} 789$ & Phycobilisome linker polypeptide & 2.8 & 52.7559 & 29,427 \\
\hline 6 & $1,2,3$ & $\operatorname{tr} \mid \mathrm{B} 5 \mathrm{VV} 49$ & Phycobilisome linker polypeptide & 2.75 & 30.90278 & 32,509 \\
\hline 7 & 2 & $\operatorname{tr} \mid \mathrm{B} 5 \mathrm{VV} 50$ & Phycobilisome linker polypeptide & 3.67 & 59.77859 & 30,834 \\
\hline 8 & 3,4 & $\operatorname{tr} \mid \mathrm{B} 5 \mathrm{~W} 2 \mathrm{H} 7$ & Phycobilisome protein & 8.72 & 55.90062 & 18,002 \\
\hline 9 & $1,2,3,4$ & tr|B5VUA1 & Phycobilisome protein & 9.49 & 80.12422 & 17,392 \\
\hline
\end{tabular}

No, number; \% Cov, \% coverture; MW (Da), molecular weight (daltons); MALDI-MS/MS, matrix-assisted laser desorption/ionization mass spectrometry.

\subsection{Effect of ExPhy on Ethanol-Induced Gastric Lesions}

The gastroprotective effect of pretreatment with ExPhy on ethanol-induced gastric lesions was determined (Table 3). In the vehicle control group, no macroscopic lesions were found (Figure 1A). In the ulcer control group, severe gastric lesions were observed in the mucosa layer, such as gastric hyperemia and thick linear hemorrhages (Figure 1B), with a UI of $13.73 \pm 1.50$. Pretreatment with ExPhy (at 100, 200, and $400 \mathrm{mg} / \mathrm{kg}$ ) and omeprazole (at $40 \mathrm{mg} / \mathrm{kg}$ ) (Figure 1C-F, respectively) significantly reduced the ulcer index of lesions compared to the ulcer control group, with values of $8.91 \pm 0.87,6.61 \pm 1.10,5.13 \pm 0.94$, and $1.32 \pm 0.96$, respectively. The decrease in the ulcer index was also expressed as a percentage of protection, being $35.10 \%, 51.87 \%, 62.62 \%$, and $90.36 \%$, respectively.

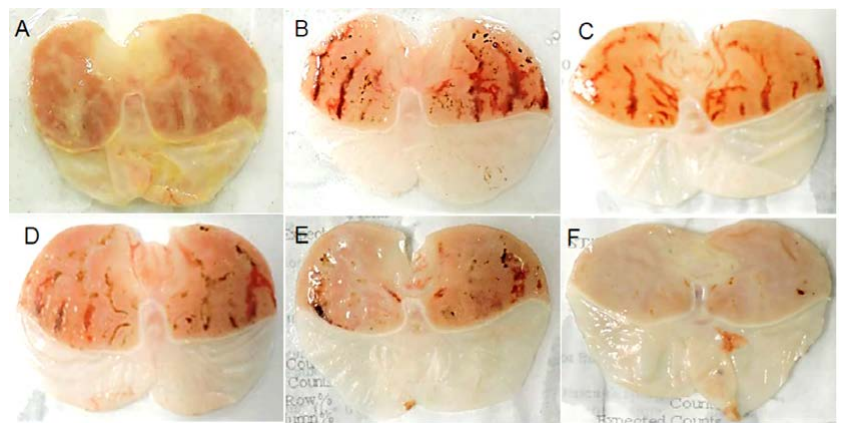

Figure 1. Gastric ulcer area of ethanol-induced ulceration in rats. (A) Vehicle control; (B) ulcer control; (C) ExPhy (100 mg/kg); (D) ExPhy (200 mg/kg); (E) ExPhy (400 mg/kg); (F) omeprazole (40 mg/kg).

\subsection{Histopathology}

The microscopic study of the vehicle control group (Figure 2A,a) shows typical gastric histoarchitecture with intact epithelium and glands. The ulcer control group, on the other hand, displayed several changes in the integrity of the gastric mucosa (Figure 2B,b), such as severe desquamation and loss of surface epithelial (mucous) cell, necrosis, vacuolization, edema and dilated gastric glands along with infiltration of inflammatory cells (neutrophils and eosinophils). Pretreatment with omeprazole decreased the gastric lesions compared to the ulcer control. The gastric mucosa exhibited focal loss of superficial gastric epithelium. The gastric glands were almost normal in 
appearance. There was mild edema with limited eosinophilic infiltration and minimal hemorrhage (Figure 2C,c). Pretreatment with ExPhy resulted in gastric lesions, characterized by focal areas of disruption in one-third of the mucosa, without a mucus layer in this zone. Nevertheless, the rest of the mucosa showed almost normal gastric glands, with mild edema and limited eosinophilic infiltration (Figure 2D,d) compared to the ulcer control.

Table 3. Effect of ExPhy and omeprazole on ulcer parameters in rats with ethanol-induced ulcers.

\begin{tabular}{cccc}
\hline Groups & Pretreatment & Ulcer Index $\left(\mathbf{m m}^{\mathbf{2}}\right)$ & Protection Percentage (\%) \\
\hline I & Vehicle control & $0^{*}$ & 0 \\
II & Ulcer control & $13.73 \pm 1.50$ & 0 \\
III & Omeprazole $(40 \mathrm{mg} / \mathrm{kg})$ & $1.32 \pm 0.96^{*}$ & 90.36 \\
IV & ExPhy $(100 \mathrm{mg} / \mathrm{kg})$ & $8.91 \pm 0.87^{*}$ & 35.10 \\
V & ExPhy $(200 \mathrm{mg} / \mathrm{kg})$ & $6.61 \pm 1.10^{*}$ & 51.87 \\
VI & ExPhy $(400 \mathrm{mg} / \mathrm{kg})$ & $5.13 \pm 0.94^{*}$ & 62.62 \\
\hline
\end{tabular}

Data are expressed as the mean $\pm \mathrm{SEM} ; n=6$ rats per group; ${ }^{*}$ indicates $p<0.05$ compared to the ulcer control group; ExPhy = extract rich in phycobiliproteins.
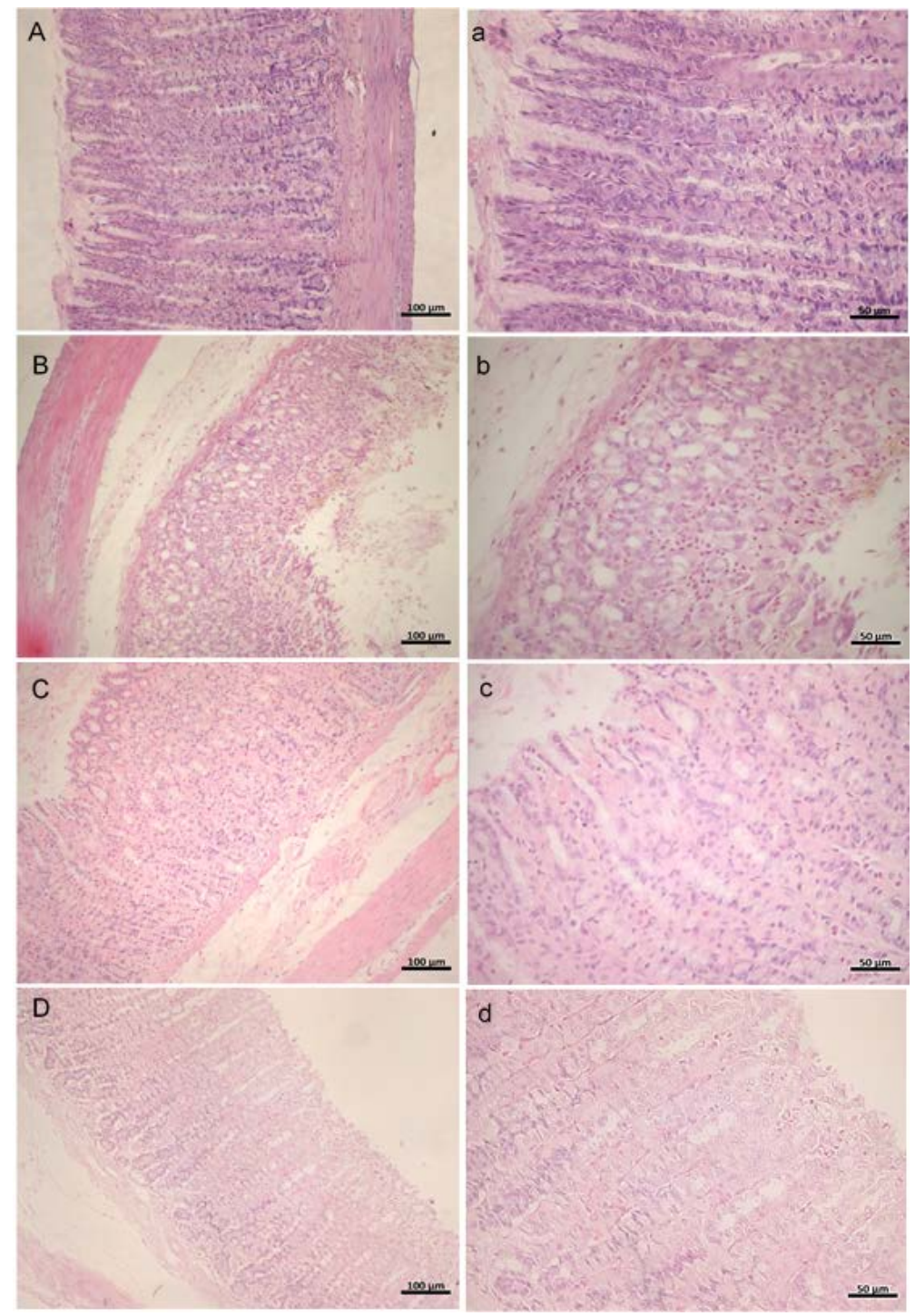

Figure 2. H\&E staining of rat gastric mucosa in ethanol-induced gastric ulcers (magnification at $20 \times$ and $40 \times) .(\mathbf{A}, \mathbf{a})$ Vehicle control; (B,b) ulcer control; (C,c) omeprazole $(40 \mathrm{mg} / \mathrm{kg}) ;(\mathbf{D}, \mathbf{d})$ ExPhy (400 mg/kg). 


\subsection{MDA and Antioxidant Enzyme Determination}

After ethanol administration, an evaluation was made of the effect of ExPhy on the activity of antioxidant enzymes (SOD, CAT, and GPx) and the level of MDA (as a lipoperoxidation index) in gastric tissue (Figure 3). The SOD enzyme activity in the ulcer control significantly decreased compared to the vehicle control. Pretreatment of rats with ExPhy $(400 \mathrm{mg} / \mathrm{kg})$ and omeprazole $(40 \mathrm{mg} / \mathrm{kg})$ significantly restored SOD activity in relation to the ulcer control. CAT activity in the stomach of the ulcer control was significantly lower than that of the vehicle control. In the groups treated with ExPhy $(400 \mathrm{mg} / \mathrm{kg})$ and omeprazole $(40 \mathrm{mg} / \mathrm{kg})$, CAT activity was significantly greater than in the ulcer control. The depletion of GPx activity observed in ulcer control was significantly reversed in rats pretreated with ExPhy $(400 \mathrm{mg} / \mathrm{kg}$ ) and omeprazole $(40 \mathrm{mg} / \mathrm{kg})$. Regarding gastric MDA, there was a significantly higher level in the ulcer control versus the vehicle control. Pretreatment with ExPhy $(400 \mathrm{mg} / \mathrm{kg}$ ) and omeprazole $(40 \mathrm{mg} / \mathrm{kg}$ ) protected against the damage found in the ulcer control and led to decreased concentrations of MDA.
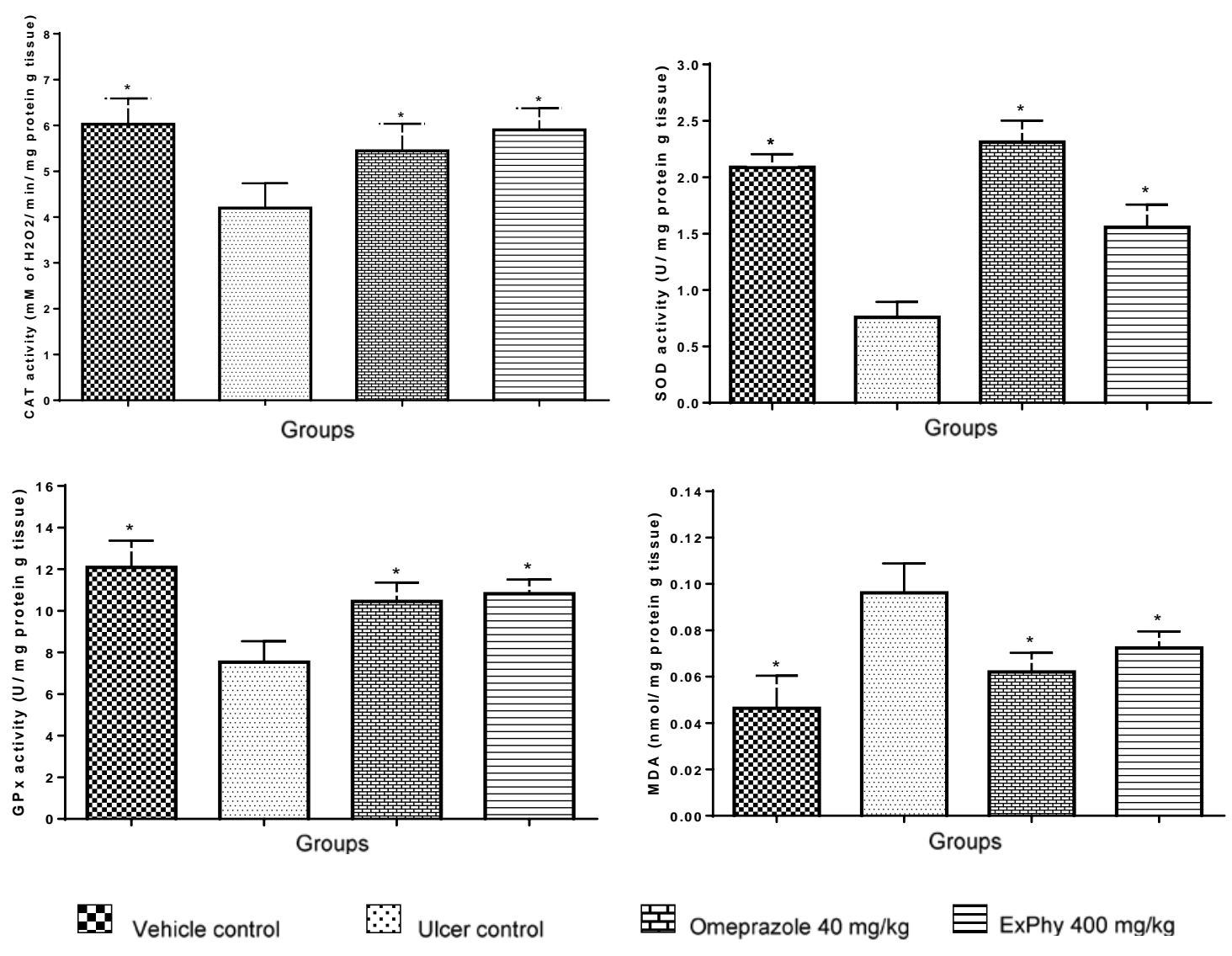

㯺 Omeprazole $40 \mathrm{mg} / \mathrm{kg}$ ExPhy $400 \mathrm{mg} / \mathrm{kg}$

Figure 3. ExPhy and omeprazole pretreatments, followed by ethanol-induced gastric ulcers, produced protective effects on the gastric mucosal activity of GPx, SOD and CAT, as well as lowering the levels of MDA compared to the ulcer control. * Indicates $p<0.05$. Data are expressed as the mean \pm SEM. ExPhy, extract rich in phycobiliproteins.

\section{Discussion}

Considering the frequency of gastric ulcers in humans and the side effects and cost of some available synthetic drugs, the use of natural products represents an important alternative for many $[43,44]$. In this sense, Spirulina maxima and ExPhy have proven to be advantageous in the treatment of various ailments in lab animals and patients. Moreover, their absence of toxicity has been demonstrated by short- and long-term studies [45]. 
The current investigation evaluated the antiulcerogenic activity of ExPhy of Am on an ethanol-induced gastric ulcer model. A determination was made of the effects of ExPhy in relation to some antioxidant and oxidative markers, along with protection against histopathological damage. C-PC and APC in ExPhy were identified and characterized by standard analytical methods (UV-VIS spectroscopy and MALDI-MS/MS).

Phycobilisomes are supramolecular complexes on the stromal surface of the thylakoid membrane in cyanobacteria (e.g., Am). These complexes, which participate in trapping light energy and transferring it within the cell, can make up to $60 \%$ of the total protein [46,47]. The antioxidant potential reported for Am may be attributed to this major class of proteins. Phycobilisomes are constituted mainly by individual protein components denominated phycobiliproteins and linker polypeptides [48]. Phycobiliproteins consist of two different polypeptides (the $\alpha$ and $\beta$ chains) that are covalently linked to bilin chromophores [49]. In this study, MALDI-MS/MS analysis corroborated that the protein bands excised from SDS-PAGE belonged to $\alpha$ and $\beta$ subunits of C-PC and APC, the main photosynthetic accessory pigments present in cyanobacteria [47]. On the other hand, the values of purity achieved for C-PC and APC from ExPhy (Table 1) can be considered good, since a purity of 0.7 is accepted as food grade [50]. Interestingly, the analysis by mass spectrometry showed the presence of other cellular proteins (see the Supplementary Materials) that probably influenced the purity of phycobiliproteins in a minor way.

Phycobiliproteins have attracted attention due to their special structure and potential therapeutic properties, either in a pure state or in protein extract. C-PC and APC are known to exert several beneficial activities, including antioxidant (shown in vitro and in vivo) [19,51,52], anti-inflammatory, and immune-stimulatory [27,53-56]. The antioxidant mechanism of phycobiliproteins has been associated with various activities: (1) ROS scavenging [25,51,52]; (2) chelating [25]; (3) neutralizing free radicals through the sulfur atom of cysteine and methionine of apophycocyanin, which can transfer hydrogen atoms or electrons to free radicals [51,57]; and (4) influencing the activity of antioxidant enzymes [58-60].

Excessive ethanol consumption is considered one of the risk factors for gastric ulcers in humans [61,62]. Its use in experimental animals allows for the evaluation of cytoprotective activity of potentially active products [63]. Different mechanisms of gastric cytoprotection have been suggested, including increased gastric mucosal blood flow, free radical scavenging, and stimulation of cell growth and repair [64]. In the current study, consistent with previous findings, administration of $80 \%$ ethanol solution by intragastric gavage produced marked damage in the gastric mucosa of rats, characterized mainly by elongated macroscopic lesions with intense hemorrhaging and hyperemia, as well as loss of mucus $[35,65,66]$. Pre-treatment of rats for eight days with ExPhy markedly attenuated gastric damage and promoted healing of gastric mucosa lesions induced by ethanol, although to a lesser extent than the standard drug, omeprazole. ExPhy provided the best protection at the highest concentration tested. These results indicate that ExPhy may have a protective effect against the ulcerative lesions induced by ethanol on gastric mucosa.

Additionally, though it was not explored presently, direct contact of phycocyanin with injured gastric mucosa possibly contributes to the healing process. There is evidence that both Spirulina and C-phycocyanin are capable of stimulating cell growth and viability, both in human keratinocytes and in a rat model [67]. These properties underlie the use of Spirulina in the development of new biomaterials for the construction of scaffolds for cell growth in the field of tissue engineering [68].

After demonstrating that ExPhy provided a protective effect against the development of ethanol-induced ulcers, the next step was to confirm these findings through a histopathological analysis of gastric tissue. In accordance with previous studies, the ulcer control group showed typical histological damage $1 \mathrm{~h}$ after ethanol administration. This damage was characterized by vascular congestion, submucosal edema formation, loss of gastric mucosa integrity, and necrotic tissue injury, as well as an inflammatory response characterized by neutrophil and eosinophil infiltration $[65,69,70]$. The aggregation of neutrophils plays a fundamental role in the process of injury and inflammation 
in the gastric mucosa due to their release of tissue-disruptive substances like proteases, leukotrienes B4 (LTB4), and reactive oxygen species [71,72]. Via NADPH oxidase, neutrophils release superoxide anions, and these in turn are metabolized into the hydroxyl radical. The latter can mediate lipid peroxidation of polyunsaturated fatty acids and cause damage to cell membranes, leading to an alteration in the structural integrity and biochemical function of membranes [73,74].

Interestingly, the microscopic study revealed a lesser extent of inflammatory infiltrate in the group of rats treated with ExPhy. Moreover, the histopathological changes triggered by ethanol were significantly diminished. The gastric mucosa showed a more regular architecture and less hemorrhaging and submucosal edema. Previous reports have confirmed the anti-inflammatory properties of phycobiliproteins. In rats with colitis treated with phycocyanin, Gonzales et al. [27] described a substantial reduction in neutrophil infiltration in colonic mucosal injury. Remirez et al. [28] evaluated the protective effect of the phycocyanin extract in the zymosan-induced arthritis model in mice, finding that treatment with phycocyanin displayed an inhibition of cellular infiltration. Further studies carried out by Romay et al. $[75,76]$ demonstrated that phycocyanin is able to inhibit the inflammatory response and edema triggered by $12-\mathrm{O}$ tetradecanoyl phorbol 13-acetate in mice, as well as reduce the LTB4 levels in arachidonic acid-induced mouse ear edema. Inhibitors of cyclooxygenase (COX) and lipooxygenase (LOX) enzymes have proven to be active in this model [77], suggesting that the mechanism of action of ExPhy for diminishing inflammatory infiltrate and edema could be linked, at least in part, to their antioxidant properties (as previously described), an inhibitory effect on cyclooxygenase-2 (COX-2), and/or the biosynthesis of LTB4.

Currently, there is consensus that alcohol intake is noxious to gastric tissue. The generation of ROS and subsequent oxidative stress is one of the major mechanisms in the pathogenesis of gastric tissue damage and ulcerogenesis induced by ethanol $[71,78]$. It has been documented that the administration of alcohol not only has necrotizing effects but also gives rise to oxidative stress by provoking injury to the mitochondria. The latter occurs through a decrease in mitochondrial membrane potential, which leads to a perturbation of the mitochondrial electron transfer system and an overproduction of $\mathrm{O}_{2}-[79,80]$. Oxidative stress is manifested as an abnormal elevation of reactive oxygen species, leading to the depletion of the antioxidant defense system (enzymatic and non-enzymatic), thus furthering damage to cell structures such as carbohydrates, nucleic acids, proteins and lipids (promoting lipid peroxidation) $[12,81]$. Potent antioxidants and free radical scavengers have been shown to inhibit oxidative stress and consequently the progression of lipid peroxidation [82,83]. Molecules with this capability include flavonoids, phenolic compounds, vitamins (tocopherol), and phycocyanin [53]. The latter is a powerful antioxidant that removes free radicals, including peroxynitrite radicals, nitric oxide radicals, peroxyl radicals, hydroxyl radicals, superoxide anion, hypochlorous oxygen, hydrogen peroxide, and synthetic radicals DPPH and ABTS. This action is given by its structure, rich in amino acids such as methionine, cysteine, and the tetrapyrolic prosthetic group, which can stabilize highly reactive species such as free radicals [60]. In addition, in vivo and in vitro models have been shown to exert antioxidant action within the cells [84]. Therefore, the administration of ExPhy in this study probably improves cellular antioxidant defenses.

In the current study, we corroborated that intragastric administration of ethanol causes severe oxidative stress in stomach tissue (ulcer control group) by significant inhibition of the activity of antioxidant enzymes such as CAT, GPx, and SOD compared to the vehicle control group. Additionally, there was a significant increase in the level of MDA, as previously reported [66,85]. MDA is commonly measured as a biomarker to assess lipid peroxidation levels in tissues [86]. ExPhy pretreatment exhibited antioxidant properties by decreasing the levels of MDA, suggesting its potential to protect against ethanol-induced lipid peroxidation in rats. Furthermore, ExPhy preserved the antioxidant activity of GPx, CAT, and SOD enzymes after ethanol administration, thus protecting the gastric mucosa.

Normally, these antioxidant enzymes provide cells with mechanisms for defending themselves against ROS damage. SOD represents the first line of defense against ROS by catalyzing the 
conversion of $\mathrm{O}_{2}$-to oxygen and $\mathrm{H}_{2} \mathrm{O}_{2}$, the latter of which is catalyzed to $\mathrm{H}_{2} \mathrm{O}$ by CAT or GPx [83]. The possibility of this protective effect being fostered by ExPhy is consistent with previous findings that phycobiliproteins engender a significant decrease in oxidative stress by increasing the antioxidant defense system and reducing the levels of lipid peroxidation in different pathologic conditions. Fernandez-Rojas et al. [60] reported the protective effect of C-PC against cisplatin-induced nephrotoxicity in CD-1 mice through the attenuation of oxidative stress and an enhancement of the activity of antioxidant enzymes. This effect was associated with the ROS-scavenging ability of C-PC. Additionally, Rodríguez-Sánchez et al. [87] found that phycobiliproteins protect renal cells against mercury-induced oxidative stress in mice. The mechanism of action suggested involves the reduction of oxidative markers and the chelating properties of phycobiliproteins. More recently, Kumari and Anbarusa [59] documented the protective action of C-PC in the rat selenite cataract model, which might be a consequence of its ability to scavenge the free radicals generated and exert an anti-apoptotic function.

In conclusion, the current results suggest a significant gastroprotective effect of ExPhy against ethanol-induced gastric damage. This protection may be related to the antioxidant properties of ExPhy by activating some enzymatic antioxidant mechanisms (SOD, CAT, and GPx), diminishing lipid peroxidation, and attenuating the inflammatory response, improving defenses against the erosive lesion that characterize the development of gastric ulcers produced by ethanol. However, further detailed studies are needed to clarify the mechanisms underlying the gastroprotective effect shown by ExPhy.

Supplementary Materials: The following are available online at http://www.mdpi.com/2072-6643/10/6/763/s1, Table S1: Additional proteins identified by MALDI-MS/MS.

Author Contributions: O.G.-G., G.A.C.-C. and R.V.G.-R. conceived and designed the experiments; O.G.-G., N.L.R.-R. and E.R.-C. performed the experiments; O.G.-G., E.R.-C., N.L.R.-R., L.Q.-C. and R.P.-P.-B. analyzed the data; R.P.-P.-B., G.A.C.-C., S.P.-G. and J.P.-R. contributed reagents/materials; O.G.-G. and G.A.C.-C. wrote the paper.

Acknowledgments: We thank Gloria Mercado for reviewing the use of English in this manuscript. This work was supported in part by the grant SIP 20160763X, I.P.N., Mexico.

Conflicts of Interest: The authors declare no conflict of interest.

\section{References}

1. Brucker, M.; Faucher, M. Pharmacologic Management of Common Gastrointestinal Health Problems in Women. J. Nurse. Midwifery 1997, 42, 145-162. [CrossRef]

2. Dimaline, R.; Varro, A. Attack and Defence in the Gastric Epithelium-A Delicate Balance. Exp. Physiol. 2007, 92, 591-601. [CrossRef] [PubMed]

3. Guslandi, M. Effects of Ethanol on the Gastric Mucosa. Dig. Dis. 1987, 5, 21-32. [CrossRef] [PubMed]

4. Maity, P.; Biswas, K.; Roy, S.; Banerjee, R.K.; Bandyopadhyay, U. Smoking and the Pathogenesis of Gastroduodenal Ulcer-Recent Mechanistic Update. Mol. Cell. Biochem. 2003, 253, 329-338. [CrossRef] [PubMed]

5. Spirt, M.J. Stress-Related Mucosal Disease: Risk Factors and Prophylactic Therapy. Clin. Ther. 2017, 26, 197-213. [CrossRef]

6. Vonkeman, H.E.; Klok, R.M.; Postma, M.J.; Brouwers, J.R.B.J.; van de Laar, M.A.F.J. Direct Medical Costs of Serious Gastrointestinal Ulcers among Users of NSAIDs. Drugs Aging 2007, 24, 681-690. [CrossRef] [PubMed]

7. Bujanda, L. The Effects of Alcohol Consumption upon the Gastrointestinal Tract. Am. J. Gastroenterol. 2000, 95, 3374-3382. [CrossRef] [PubMed]

8. Bode, C.; Bode, J.C. Alcohol's Role in Gastrointestinal Tract Disorders. Alcohol. Health Res. World 1997, 21, 76-83. [PubMed]

9. Cadirci, E.; Suleyman, H.; Aksoy, H.; Halici, Z.; Ozgen, U.; Koc, A.; Ozturk, N. Effects of Onosma Armeniacum Root Extract on Ethanol-Induced Oxidative Stress in Stomach Tissue of Rats. Chem. Biol. Interact. 2007, 170, 40-48. [CrossRef] [PubMed] 
10. Alimi, H.; Hfaiedh, N.; Bouoni, Z.; Sakly, M.; Ben Rhouma, K. Evaluation of Antioxidant and Antiulcerogenic Activities of Opuntia Ficus Indica F. Inermis Flowers Extract in Rats. Environ. Toxicol. Pharmacol. 2011, 32, 406-416. [CrossRef] [PubMed]

11. Melchiorri, D.; Sewerynek, E.; Reiter, R.J.; Ortiz, G.G.; Poeggeler, B.; Nisticò, G. Suppressive Effect of Melatonin Administration on Ethanol-Induced Gastroduodenal Injury in Rats in Vivo. Br. J. Pharmacol. 1997, 121, 264-270. [CrossRef] [PubMed]

12. Pan, J.-S.; He, S.-Z.; Xu, H.-Z.; Zhan, X.-J.; Yang, X.-N.; Xiao, H.-M.; Shi, H.-X.; Ren, J.-L. Oxidative Stress Disturbs Energy Metabolism of Mitochondria in Ethanol-Induced Gastric Mucosa Injury. World J. Gastroenterol. 2008, 14, 5857-5867. [CrossRef] [PubMed]

13. Arda-Pirincci, P.; Bolkent, S.; Yanardag, R. The Role of Zinc Sulfate and Metallothionein in Protection Against Ethanol-Induced Gastric Damage in Rats. Dig. Dis. Sci. 2006, 51, 2353-2360. [CrossRef] [PubMed]

14. Vonshak, A. Spirulina Platensis Arthrospira: Physiology, Cell-Biology and Biotechnology; Taylor Francis Press: London, UK, 1997; p. 151.

15. Al-Dhabi, N.A. Heavy Metal Analysis in Commercial Spirulina Products for Human Consumption. Saudi J. Biol. Sci. 2013, 20, 383-388. [CrossRef] [PubMed]

16. Campanella, L.; Crescentini, G.; Avino, P. Chemical Composition and Nutritional Evaluation of Some Natural and Commercial Food Products Based on Spirulina. Analusis 1999, 27, 533-540. [CrossRef]

17. Mao, T.K.; van de Water, J.; Gershwin, M.E. Effect of Spirulina on the Secretion of Cytokines from Peripheral Blood Mononuclear Cells. J. Med. Food 2000, 3, 135-140. [CrossRef] [PubMed]

18. Hernández-Corona, A.; Nieves, I.; Meckes, M.; Chamorro, G.; Barron, B.L. Antiviral Activity of Spirulina Maxima against Herpes Simplex Virus Type 2. Antivir. Res. 2002, 56, 279-285. [CrossRef]

19. Piñero Estrada, J. Antioxidant Activity of Different Fractions of Spirulina Platensis Protean Extract. Farmaco 2001, 56, 497-500. [CrossRef]

20. Chamorro-Cevallos, G.; Garduño-Siciliano, L.; Barrón, B.L.; Madrigal-Bujaidar, E.; Cruz-Vega, D.E.; Pages, N. Chemoprotective Effect of Spirulina (Arthrospira) against Cyclophosphamide-Induced Mutagenicity in Mice. Food Chem. Toxicol. 2008, 46, 567-574. [CrossRef] [PubMed]

21. Juárez-Oropeza, M.A.; Mascher, D.; Torres-Durán, P.V.; Farias, J.M.; Paredes-Carbajal, M.C. Effects of Dietary Spirulina on Vascular Reactivity. J. Med. Food 2009, 12, 15-20. [CrossRef] [PubMed]

22. Jatav, S.K.; Kulshrestha, A.; Zacharia, A.; Singh, N.; Tejovathi, G.; Bisen, P.S.; Prasad, G.B.K.S. Spirulina Maxima Protects Liver From Isoniazid and Rifampicin Drug Toxicity. J. Evid. Based. Complement. Altern. Med. 2014, 19, 189-194. [CrossRef] [PubMed]

23. Sinanoglu, O.; Yener, A.N.; Ekici, S.; Midi, A.; Aksungar, F.B. The Protective Effects of Spirulina in Cyclophosphamide Induced Nephrotoxicity and Urotoxicity in Rats. Urology 2012, 80, 1392.e1-1392.e6. [CrossRef] [PubMed]

24. Miranda, M.S.; Cintra, R.G.; Barros, S.B.M.; Mancini-Filho, J. Antioxidant Activity of the Microalga Spirulina Maxima. Braz. J. Med. Biol. Res. 1998, 31, 1075-1079. [CrossRef] [PubMed]

25. Bermejo-Bescós, P.; Piñero-Estrada, E.; Villar del Fresno, Á.M. Neuroprotection by Spirulina Platensis Protean Extract and Phycocyanin against Iron-Induced Toxicity in SH-SY5Y Neuroblastoma Cells. Toxicol. Vitr. 2008, 22, 1496-1502. [CrossRef] [PubMed]

26. Romay, C.; Delgado, R.; Remirez, D.; Gonzalez, R.; Rojas, A. Effects of Phycocyanin Extract on Tumor Necrosis Factor- $\alpha$ and Nitrite Levels in Serum of Mice Treated with Endotoxin. Arzneimittelforschung 2001, 51, 733-736. [CrossRef] [PubMed]

27. González, R.; Rodríguez, S.; Romay, C.; Ancheta, O.; González, A.; Armesto, J.; Remirez, D.; Merino, N. Anti-Inflammatory Activity of Phycocyanin Extract in Acetic Acid-Induced Colitis in Rats. Pharmacol. Res. 1999, 39, 55-59. [CrossRef] [PubMed]

28. Remirez, D.; González, A.; Merino, N.; González, R.; Ancheta, O.; Romay, C.; Rodríguez, S. Effect of Phycocyanin in Zymosan-Induced Arthritis in Mice-Phycocyanin as an Antiarthritic Compound. Drug Dev. Res. 1999, 48, 70-75. [CrossRef]

29. Cruz de Jesús, V. Methods for Extraction, Isolation and Purification of C-Phycocyanin: 50 Years of Research in Review. Int. J. Food Nutr. Sci. 2016, 3, 1-10.

30. Bennett, A.; Bogorad, L. Complementary Chromatic Adaption in a Filamentous Blue-Green Alga. J. Cell. Biol. $1973,58,419-435$. 
31. Boussiba, S.; Richmond, A.E. Isolation and Characterization of Phycocyanins from the Blue-Green Alga Spirulina Platensis. Arch. Microbiol. 1979, 120, 155-159. [CrossRef]

32. Gallagher, S.R. One-Dimensional SDS Gel Electrophoresis of Proteins. Curr. Protoc. Protein Sci. 2012, 1, 1-44.

33. Shevchenko, A.; Tomas, H.; Havli, J.; Olsen, J.V.; Mann, M. In-Gel Digestion for Mass Spectrometric Characterization of Proteins and Proteomes. Nat. Protoc. 2007, 1, 2856. [CrossRef] [PubMed]

34. Shilov, I.V.; Seymour, S.L.; Patel, A.A.; Loboda, A.; Tang, W.H.; Keating, S.P.; Hunter, C.L.; Nuwaysir, L.M.; Schaeffer, D.A. The Paragon Algorithm, a Next Generation Search Engine That Uses Sequence Temperature Values and Feature Probabilities to Identify Peptides from Tandem Mass Spectra. Mol. Cell. Proteom. 2007, 6, 1638-1655. [CrossRef] [PubMed]

35. Almasaudi, S.B.; El-Shitany, N.A.; Abbas, A.T.; Abdel-Dayem, U.A.; Ali, S.S.; Al Jaouni, S.K.; Harakeh, S. Antioxidant, Anti-Inflammatory, and Antiulcer Potential of Manuka Honey against Gastric Ulcer in Rats. Oxid. Med. Cell. Longev. 2016, 2016, 1-10. [CrossRef] [PubMed]

36. Alirezaei, M.; Dezfoulian, O.; Neamati, S.; Rashidipour, M.; Tanideh, N.; Kheradmand, A. Oleuropein Prevents Ethanol-Induced Gastric Ulcers via Elevation of Antioxidant Enzyme Activities in Rats. J. Physiol. Biochem. 2012, 68, 583-592. [CrossRef] [PubMed]

37. Adinortey, M.B.; Ansah, C.; Galyuon, I.; Nyarko, A. In Vivo Models Used for Evaluation of Potential Antigastroduodenal Ulcer Agents. Ulcers 2013, 2013, 1-12. [CrossRef]

38. Paglia, D.E.; Valentine, W.N. Studies on the Quantitative and Qualitative Characterization of Erytrocyte Glutathione Peroxidase. J. Lab. Clin. Med. 1967, 70, 158-169. [PubMed]

39. Mccord, J.; Fridovich, I.; McCOrd, J.M.; Fridovich, I. Superoxide Dismutase. An Enzymic Function for Erythrocuprein (Hemocuprein). J. Biol. Chem. J. Biol. Chem. 1969, 244, 6049-6055. [PubMed]

40. Aebi, H. Catalase in vitro. In Oxygen Radicals in Biological Systems; Academic Press: Cambridge, MA, USA, 1984; Volume 105, pp. 121-126.

41. Bradford, M.M. A Rapid and Sensitive Method for the Quantitation of Microgram Quantities of Protein Utilizing the Principle of Protein-Dye Binding. Anal. Biochem. 1976, 72, 248-254. [CrossRef]

42. Esterbauer, H.; Cheeseman, K.H. Determination of Aldehydic Lipid Peroxidation Products: Malonaldehyde and 4-Hydroxynonenal. In Oxygen Radicals in Biological Systems Part B: Oxygen Radicals and Antioxidants; Academic Press: Cambridge, MA, USA, 1990; Volume 186, pp. 407-421.

43. Vimala, G.; Gricilda Shoba, F. A Review on Antiulcer Activity of Few Indian Medicinal Plants. Int. J. Microbiol. 2014, 2014, 1-14. [CrossRef] [PubMed]

44. Al-Wajeeh, N.S.; Halabi, M.F.; Hajrezaie, M.; Dhiyaaldeen, S.M.; Bardi, D.A.; Salama, S.M.; Rouhollahi, E.; Karimian, H.; Abdolmalaki, R.; Azizan, A.H.S.; et al. The Gastroprotective Effect of Vitex Pubescens Leaf Extract against Ethanol-Provoked Gastric Mucosal Damage in Sprague-Dawley Rats. PLoS ONE 2016, 11, 179072. [CrossRef] [PubMed]

45. Gutiérrez-Salmeán, G.; Fabila-Castillo, L.; Chamorro-Cevallos, G. Aspectos Nutricionales Y Toxicológicos de Spirulina (Arthrospira). Nutr. Hosp. 2015, 32, 34-40. [PubMed]

46. Viskari, P.J.; Colyer, C.L. Separation and Quantitation of Phycobiliproteins Using Phytic Acid in Capillary Electrophoresis with Laser-Induced Fluorescence Detection. J. Chromatogr. A 2002, 972, 269-276. [CrossRef]

47. Bryant, D.A.; Guglielmi, G.; de Marsac, N.T.; Castets, A.M.; Cohen-Bazire, G. The Structure of Cyanobacterial Phycobilisomes: A Model. Arch. Microbiol. 1979, 123, 113-127. [CrossRef]

48. Singh, N.K.; Sonani, R.R.; Prasad Rastogi, R.; Madamwar, D. The Phycobilisomes: An Early Requisite for Efficient Photosynthesis in Cyanobacteria. EXCLI J. 2015, 14, 268-289. [PubMed]

49. Scheer, H.; Zhao, K.H. Biliprotein Maturation: The Chromophore Attachment. Mol. Microbiol. 2008, 68, 263-276. [CrossRef] [PubMed]

50. Rito-Palomares, M.; Nuez, L.; Amador, D. Practical Application of Aqueous Two-Phase Systems for the Development of a Prototype Process for c-Phycocyanin Recovery from Spirulina Maxima. J. Chem. Technol. Biotechnol. 2001, 76, 1273-1280. [CrossRef]

51. Cherdkiatikul, T.; Suwanwong, Y. Production of the $\alpha$ and $\beta$ Subunits of Spirulina Allophycocyanin and C-Phycocyanin in Escherichia Coli: A Comparative Study of Their Antioxidant Activities. J. Biomol. Screen. 2014, 19, 959-965. [CrossRef] [PubMed]

52. Romay, C.; Armesto, J.; Remirez, D.; González, R.; Ledon, N.; García, I. Antioxidant and Anti-Inflammatory Properties of C-Phycocyanin from Blue-Green Algae. Inflamm. Res. 1998, 47, 36-41. [CrossRef] [PubMed] 
53. Romay, C.; Gonzalez, R.; Ledon, N.; Remirez, D.; Rimbau, V. C-Phycocyanin: A Biliprotein with Antioxidant, Anti-Inflammatory and Neuroprotective Effects. Curr. Protein Pept. Sci. 2003, 4, 207-216. [CrossRef] [PubMed]

54. Reddy, M.C.; Subhashini, J.; Mahipal, S.V.; Bhat, V.B.; Srinivas Reddy, P.; Kiranmai, G.; Madyastha, K.; Reddanna, P. C-Phycocyanin, a Selective Cyclooxygenase-2 Inhibitor, Induces Apoptosis in Lipopolysaccharide-Stimulated RAW 264.7 Macrophages. Biochem. Biophys. Res. Commun. 2003, 304, 385-392. [CrossRef]

55. Belay, A. The Potential Application of Spirulina (Arthrospira) as a Nutritional Health and Therapeutic Supplement in Health Management. J. Am. Nutr. Assoc. 2002, 5, 27-48.

56. El Sheikh, S.M.; Shalaby, M.A.M.; Hafez, R.A.; Metwally, W.S.A.; El-Ayoty, Y.M. The Immunomodulatory Effects of Probiotic Bacteria on Peripheral Blood Mononuclear Cells (PBMCS) of Allergic Patients. Am. J. Immunol. 2014, 10, 116-130. [CrossRef]

57. Atmaca, G. Antioxidant Effects of Sulfur-Containing Amino Acids. Yonsei Med. J. 2004, 45, 776-788. [CrossRef] [PubMed]

58. Ou, Y.; Zheng, S.; Lin, L.; Jiang, Q.; Yang, X. Chemico-Biological Interactions Protective Effect of C-Phycocyanin against Carbon Tetrachloride-Induced Hepatocyte Damage in Vitro and in Vivo. Chem. Biol. Interact. 2010, 185, 94-100. [CrossRef] [PubMed]

59. Kumari, R.P.; Anbarasu, K. Protective Role of C-Phycocyanin Against Secondary Changes During Sodium Selenite Mediated Cataractogenesis. Nat. Products Bioprospect. 2014, 4, 81-89. [CrossRef] [PubMed]

60. Fernandez-Rojas, B.; Medina-Campos, O.N.; Hernandez-Pando, R.; Negrette-Guzman, M.; Huerta-Yepez, S.; Pedraza-Chaverri, J. C-Phycocyanin Prevents Cisplatin-Induced Nephrotoxicity through Inhibition of Oxidative Stress. Food Funct. 2014, 5, 480-490. [CrossRef] [PubMed]

61. Lulu, D.J.; Dragstedt, L.R. Massive Bleeding Due to Acute Hemorrhagic Gastritis. Arch. Surg. 1970, 101, 550-554. [CrossRef] [PubMed]

62. Søreide, K.; Thorsen, K.; Harrison, E.M.; Bingener, J.; Møller, M.H.; Ohene-Yeboah, M.; Søreide, J.A. Perforated Peptic Ulcer. Lancet 2015, 386, 1288-1298. [CrossRef]

63. Bighetti, A.E.; Antônio, M.A.; Kohn, L.K.; Rehder, V.L.G.; Foglio, M.A.; Possenti, A.; Vilela, L.; Carvalho, J.E. Antiulcerogenic Activity of a Crude Hydroalcoholic Extract and Coumarin Isolated from Mikania Laevigata Schultz Bip. Phytomedicine 2005, 12, 72-77. [CrossRef] [PubMed]

64. Diniz D'Souza, R.S.; Dhume, V.G. Gastric Cytoprotection. Indian J. Physiol. Pharmacol. 1991, 35, 88-98.

65. Ben Barka, Z.; Tlili, M.; Alimi, H.; Ben Miled, H.; Ben Rhouma, K.; Sakly, M.; Ksouri, R.; Schneider, Y.J.; Tebourbi, O. Protective Effects of Edible Rhus Tripartita (Ucria) Stem Extract against Ethanol-Induced Gastric Ulcer in Rats. J. Funct. Foods 2017, 30, 260-269. [CrossRef]

66. Antonisamy, P.; Duraipandiyan, V.; Aravinthan, A.; Al-Dhabi, N.A.; Ignacimuthu, S.; Choi, K.C.; Kim, J.H. Protective Effects of Friedelin Isolated from Azima Tetracantha Lam. against Ethanol-Induced Gastric Ulcer in Rats and Possible Underlying Mechanisms. Eur. J. Pharmacol. 2015, 750, 167-175. [CrossRef] [PubMed]

67. Sevimli Gur, C.; Erdogan, D.K.; Onbasılar, I.; Atilla, P.; Cakar, N.; Deliloglu Gurhan, I. In Vitro and in Vivo Investigations of the Wound Healing Effect of Crude Spirulina Extract and C-Phycocyanin. J. Med. Plants Res. 2013, 7, 425-433.

68. Morais, M.; da Silva Vaz, B.; Morais, E.; Costa, J.A. Biological Effects of Spirulina (Arthrospira) Biopolymers and Biomass in the Development of Nanostructured Scaffolds. BioMed Res. Int. 2014, 2014, 1-9. [CrossRef] [PubMed]

69. Zakaria, Z.A.; Abdul Hisam, E.E.; Rofiee, M.S.; Norhafizah, M.; Somchit, M.N.; Teh, L.K.; Salleh, M.Z. In Vivo Antiulcer Activity of the Aqueous Extract of Bauhinia Purpurea Leaf. J. Ethnopharmacol. 2011, 137, 1047-1054. [CrossRef] [PubMed]

70. Rozza, A.L.; Hiruma-Lima, C.A.; Takahira, R.K.; Padovani, C.R.; Pellizzon, C.H. Effect of Menthol in Experimentally Induced Ulcers: Pathways of Gastroprotection. Chem. Biol. Interact. 2013, 206, 272-278. [CrossRef] [PubMed]

71. Yao, J. Tiao He Yi Wei Granule, a Traditional Chinese Medicine, against Ethanol-Induced Gastric Ulcer in Mice. Evidence-based Complement. Altern. Med. 2015, 2015, 1-8.

72. Hamauzu, Y.; Forest, F.; Hiramatsu, K.; Sugimoto, M. Effect of Pear (Pyrus Communis L.) Procyanidins on Gastric Lesions Induced by HCl/ethanol in Rats. Food Chem. 2007, 100, 255-263. [CrossRef] 
73. Naito, Y.; Yoshikawa, T.; Matsuyama, K.; Yagi, N.; Arai, M.; Nakamura, Y.; Kaneko, T.; Nishimura, S.; Yoshida, N.; Kondo, M. Role of Lipid Peroxidation and Neutrophil Accumulation in the Gastric Mucosal Injury Induced by Aspirin- $\mathrm{HCl}$ in Rats Effect of Roxatidine, a Histamine H2receptor Antagonist with Antioxidative Properties. Pathophysiology 1995, 2, 1-8. [CrossRef]

74. Kobayashi, T.; Ohta, Y.; Yoshino, J.; Nakazawa, S. Teprenone Promotes the Healing of Acetic Acid-Induced Chronic Gastric Ulcers in Rats by Inhibiting Neutrophil Infiltration and Lipid Peroxidation in Ulcerated Gastric Tissues. Pharmacol. Res. 2001, 43, 23-30. [CrossRef] [PubMed]

75. Romay, C.; Ledón, N.; González, R. Further Studies on Anti-Inflammatory Activity of Phycocyanin in Some Animal Models of Inflammation. Inflamm. Res. 1998, 47, 334-338. [CrossRef] [PubMed]

76. Romay, C.; Ledón, N.; González, R. Phycocyanin Extract Reduces Leukotriene B4 Levels in Arachidonic Acid-Induced Mouse-Ear Inflammation Test. J. Pharm. Pharmacol. 1999, 51, 641-642. [CrossRef] [PubMed]

77. Carlson, R.P.; Lynn, O.-D.; Chang, J.; Lewis, A.J. Modulation of Mouse Ear Edema by Cyclooxygenase and Lipoxygenase Inhibitors and other Pharmacologic Agents. Agents Actions 1985, 17, 197-204. [CrossRef] [PubMed]

78. El-Naga, R.N. Apocynin Protects against Ethanol-Induced Gastric Ulcer in Rats by Attenuating the Upregulation of NADPH Oxidases 1 and 4. Chem. Biol. Interact. 2015, 242, 317-326. [CrossRef] [PubMed]

79. Sun, Q.; Zhong, W.; Zhang, W.; Zhou, Z. Defect of Mitochondrial Respiratory Chain Is a Mechanism of ROS Overproduction in a Rat Model of Alcoholic Liver Disease: Role of Zinc Deficiency. Am. J. Physiol. Gastrointest. Liver Physiol. 2016, 310, G205-G214. [CrossRef] [PubMed]

80. Tamura, M.; Matsui, H.; Kaneko, T.; Hyodo, I. Alcohol Is an Oxidative Stressor for Gastric Epithelial Cells: Detection of Superoxide in Living Cells. J. Clin. Biochem. Nutr. 2013, 53, 75-80. [CrossRef] [PubMed]

81. Mittal, M.; Siddiqui, M.R.; Tran, K.; Reddy, S.P.; Malik, A.B. Reactive Oxygen Species in Inflammation and Tissue Injury. Antioxid. Redox Signal. 2014, 20, 1126-1167. [CrossRef] [PubMed]

82. Ligumsky, M.; Sestieri, M.; Okon, E.; Ginsburg, I. Antioxidants Inhibit Ethanol-Induced Gastric Injury in the Rat: Role of Manganese, Glycine, and Carotene. Scand. J. Gastroenterol. 1995, 30, 854-860. [CrossRef]

83. Neamati, S.; Alirezaei, M.; Kheradmand, A. Ghrelin Acts as an Antioxidant Agent in the Rat Kidney. Int. J. Pept. Res. Ther. 2011, 17, 239. [CrossRef]

84. Li, X.L.; Xu, G.; Chen, T.; Wong, Y.S.; Zhao, H.L.; Fan, R.R.; Gu, X.M.; Tong, P.C.Y.; Chan, J.C.N. Phycocyanin Protects INS-1E Pancreatic Beta Cells against Human Islet Amyloid Polypeptide-Induced Apoptosis through Attenuating Oxidative Stress and Modulating JNK and P38 Mitogen-Activated Protein Kinase Pathways. Int. J. Biochem. Cell Biol. 2009, 41, 1526-1535. [CrossRef] [PubMed]

85. Jeon, W.-Y.; Shin, I.-S.; Shin, H.-K.; Lee, M.-Y. Gastroprotective Effect of the Traditional Herbal Medicine, Sipjeondaebo-Tang Water Extract, against Ethanol-Induced Gastric Mucosal Injury. BMC Complement. Altern. Med. 2014, 14, 373. [CrossRef] [PubMed]

86. Dursun, H.; Bilici, M.; Albayrak, F.; Ozturk, C.; Saglam, M.B.; Alp, H.H.; Suleyman, H. Antiulcer Activity of Fluvoxamine in Rats and Its Effect on Oxidant and Antioxidant Parameters in Stomach Tissue. BMC Gastroenterol. 2009, 9, 1-10. [CrossRef] [PubMed]

87. Rodriguez-Sanchez, R.; Ortiz-Butron, R.; Blas-Valdivia, V.; Hernandez-Garcia, A.; Cano-Europa, E. Phycobiliproteins or C-Phycocyanin of Arthrospira (Spirulina) Maxima Protect against $\mathrm{HgCl}_{2}$-Caused Oxidative Stress and Renal Damage. Food Chem. 2012, 135, 2359-2365. [CrossRef] [PubMed]

(C) 2018 by the authors. Licensee MDPI, Basel, Switzerland. This article is an open access article distributed under the terms and conditions of the Creative Commons Attribution (CC BY) license (http://creativecommons.org/licenses/by/4.0/). 